\title{
Pequenas e médias empresas exportadoras: fatores discriminantes e condicionantes de permanência na atividade
}

\author{
Heloisa Rosa Carvalho \\ Departamento de Administraçáo e Economia (DAE) \\ da Universidade Federal de Lavras (UFLA)
}

\section{Palavras-chave}

exportação, continuidade, pequenas e médias empresas, Sul de Minas, inovação tecnológica.

Classificação JEL C25, F19, M16

\section{Key Words}

exports, continuity, small and medium-sized enterprises,

South of Minas, technological innovation.

JEL Classification C25, F19, M16.

\section{Resumo}

Procurou-se identificar os fatores discriminantes entre empresas exportadoras contínuas e descontínuas do Sul de Minas Gerais em relação a variáveis do ambiente externo, às características internas e às de inovação tecnológica. Um modelo logit binário foi definido para pesquisar os determinantes do desempenho exportador. Os resultados mostraram que os fatores externos à empresa não discriminam e nem condicionam a permanência na atividade de exportação. Algumas características das firmas discriminam as duas subamostras e têm impacto direto na permanência na atividade exportadora. Quanto à adoção de inovações tecnológicas, os resultados revelaram que as empresas contínuas são mais intensivas ao inovar em produto, em processo e organizacionalmente. Entretanto, nem todos os itens discriminantes das subamostras quanto à capacidade tecnológica explicam positiva e significativamente a permanência das empresas no mercado exportador.

\author{
Marilia Fernandes Maciel Gomes \\ Departamento de Economia Rural (DER) \\ da Universidade Federal de Viçosa (UFV) \\ João Eustáquio de Lima \\ Departamento de Economia Rural (DER) \\ da Universidade Federal de Viçosa (UFV)
}

\section{Abstract}

This study identified the discriminating factors among continuous and intermittent exporting firms from the South of Minas, regarding variables from the external environment, the internal characteristics and technological innovation. A binary logit model was defined to research the determinants of exporting performance. The results showed that firm's external factors do not discriminate or condition continuation of exporting activities. Some characteristics of the firms discriminate between the two sub samples and have direct impact on continuation of exporting activities (performance measures). Regarding the adoption of technological innovations, the results revealed that continuous exporting firms are more intensive in product, process and organizational innovation. However, not all discriminating items of the sub samples refer to technological capacity; explain positively and with significance the firm's continuation on the exporting market. 


\section{1_Introdução}

As micros, pequenas e médias empresas (MPMEs) representam parcela significativa do PIB brasileiro, contribuem para a geração de emprego e para o desenvolvimento econômico e local e podem ser vistas como estratégia para ampliar as exportaçóes nacionais. $\mathrm{Na}$ regiáo Sudeste do país, encontra-se mais da metade $(50,9 \%)$ de todos os estabelecimentos de micro e de pequeno porte (Sebrae, 2008).

Minas Gerais configura-se como um dos maiores Estados, em termos econômicos, com o total de 262.834 empresas com representação nos municípios do Estado, das quais 257.752 são micros e pequenas (Sebrae, 2007). É o segundo maior exportador, com crescimento das exportações acima da média nacional. Entre as dez regióes de planejamento, conforme metodologia utilizada pela Fundação João Pinheiro para estimativa do Produto Interno Bruto (PIB) regional, a região Sul do Estado é a segunda maior em número de municípios e empresas exportadoras, além do volume exportado.

A importância das exportaçóes para o Estado de Minas Gerais e, em especial, para a regiāo Sul do Estado, aliada aos problemas enfrentados pelas pequenas e pelas médias empresas inseridas numa economia globalizada, assim como a escassez de número de trabalhos e estudos voltados para os aspectos do desempenho exportador das micros, pequenas e médias empresas, torna relevante avaliar os fatores que discriminam as empresas exportadoras contínuas das descontinuas e que são capazes de condicionar sua permanência na atividade de exportação.

A empresa exportadora necessita tanto de recursos como de capacidades administrativas que garantam a competitividade do produto no mercado externo. Os fatores responsáveis pelas diferenças no desempenho exportador das empresas podem estar relacionados com a percepção dos administradores dessas empresas do ambiente externo em que elas estão inseridas, mas, principalmente, com os recursos de cada firma em particular, como suas características, e a opção por adoção tecnológica.

Em face da importância desse segmento de empresas para a economia nacional e da expressividade do Estado de Minas Gerais nas exportações brasileiras, é pertinente questionar: os fatores externos e internos, em especial os relacionados à inovação tecnológica, diferenciam as micros, pequenas e médias empresas exportadoras contínuas das descontínuas? Esses fatores discriminan- 
tes são capazes de determinar e explicar a permanência dessas empresas na atividade exportadora?

Este estudo foi realizado com o objetivo de responder a essas questóes, com a finalidade de descrever e comparar as características das empresas exportadoras contínuas e descontínuas sul-mineiras, identificando os fatores discriminantes e os condicionantes do desempenho exportador (continuidade exportadora) e está estruturado da seguinte maneira: além desta parte introdutória, na segunda parte, apresenta-se a estrutura teórica e conceitual utilizada. Na terceira parte, descreve-se a metodologia, e, na quarta parte, a análise dos resultados. Por último, as principais conclusóes.

\section{2_Visão da firma baseada em recursos (VBR): histórico e conceitos-chave}

A teoria de recursos é um paradigma que surgiu da administração estratégica, focalizada em como a vantagem competitiva contínua é gerada pelo pacote sem igual de recursos no interior da empresa (Dhanaraj; Beamish, 2003).

A teoria da visão da firma basea$\mathrm{da}$ em recursos (VBR) ou, originalmente, resource-based view of the firm (RBV), tem como marco inicial a publicação de
Penrose (1980), na qual se encontram as seguintes contribuiçóes conceituais: a) a firma vista como uma coleção de recursos produtivos; b) a competitividade baseada na heterogeneidade dos seus recursos; e c) os recursos produtivos incorporam os recursos intangíveis, como, por exemplo, habilidades gerenciais.

Contudo, um dos primeiros trabalhos em que se adotou explicitamente a denominação resource-based-view foi o de Wernerfelt (1984), já na década de 1980. Em seu artigo, o autor faz um paralelo entre a visão tradicional baseada em produtos e a visão baseada em recursos, conceituando recursos como qualquer coisa que possa ser pensada como uma força ou uma fraqueza de determinada empresa (Wernerfelt, 1984).

Partindo do conceito de "recursos", um corpo significativo da literatura tem se dedicado a classificar e a categorizar recursos de uma empresa sob várias formas, desde fatores de produção comuns até ativos altamente diferenciados. Mas, de forma geral, os autores que pesquisam "recursos" classificam-nos em três categorias: ativos tangíveis, ativos intangíveis e capacidades.

Ansoff (1977) estabelece três tipos de recurso básico: físicos, como matérias-primas, máquinas e equipamentos; monetários, compreendendo a moeda e 
o crédito; e humanos, incluindo a equipe técnica e gerencial da empresa.

Para Wernerfelt (1984), os recursos podem ser tangíveis ou intangíveis e estão vinculados semipermanentemente à empresa. Burlamaqui e Proença (2003) incluem nos recursos tangíveis as propriedades, as instalaçôes, as matérias-primas e outros. Já os recursos intangíveis abrangem atributos como marcas, cultura, conhecimentos tecnológicos, patentes, aprendizado e experiência acumulados, entre outros. Para esses autores, os recursos intangíveis assumem papel mais importante na manutenção da vantagem competitiva, em função de muitos deles se tornarem mais fortes com o tempo.

No início da década de 1990, Barney (1991) introduziu a capacidade como fonte de recursos e os classificou em três categorias: capital físico, capital humano e capital organizacional. Mas, para o autor, nem todos os recursos poderiam ser considerados fonte de vantagem competitiva sustentável. Para que se tornassem vantagem competitiva sustentável, os recursos específicos de uma firma deveriam atender a quatro requisitos: serem valiosos, permitindo que a empresa explorasse as oportunidades que aparecessem; serem raros ou escassos e não pudessem ser encontrados em grande número de empresas; serem difíceis de imitar, ou seja, que as empresas que não os possuíssem não pudessem obtê-los e, por último, não possuírem substitutos. Dessa forma, as empresas que tivessem recursos com tais características e implementassem estratégias que os explorassem poderiam alcançar vantagem competitiva em relação aos seus concorrentes.

Grant (1991) ampliou as categorias de recursos propostas por Barney e incluiu também recursos tecnológicos e reputação. Além disso, estabeleceu uma distinçẫo entre recursos e capacidades:

Resources are inputs into the production process - they are the basic units of analysis. The individual resources of the firm include items of capital equipment, skills of individual employees, patents, brand names, finance, and so on. But, on their own, few resources are productive. Productive activity requires the cooperation and coordination of teams of resources. A capability is the capacity for a team of resources to perform some task or activity. While resources are the source of a firm's capabilities, capabilities are the main source of its competitive advantage (GRANT, 1991, p. 118-119).

A capacidade de uma empresa é a utilização conjunta de recursos e, para a maioria das empresas, os ativos baseados em capacidades mais importantes são os 
relacionados à integração de capacidades funcionais individuais, resultando em competências essenciais. Essas competências permitem que as firmas realizem inovações, interferindo de forma ativa nos mercados em que atuam e sendo capazes de expandir para conquistar novos mercados (Prahalad; Hamel, 1990).

Para Andersen e Kheam (1998), a visão baseada em recurso pode prover um suporte teórico para modelos de internacionalização. Assim, dentro da perspectiva teórica da VBR, podem-se examinar alguns dos determinantes ao nível da firma do desempenho exportador e, mais especificamente, o papel e a importância das atividades inovadoras.

\section{1_Inovação tecnológica e vantagem competitiva}

Segundo os modelos tradicionais de comércio internacional, formulados por Adam Smith, David Ricardo e Heckscher-Ohlin-Samuelson, o comércio trazia benefícios recíprocos para os países, e as trocas externas eram determinadas pela diferença na dotação de fatores. Tratava de uma realidade bastante simplificada, na qual o estoque de recursos e a produtividade eram dados. No entanto, no mundo real, na busca por maiores lucros, as empresas inovam, mudando tanto o estoque relativo de recursos quanto a produtividade.
Schumpeter (1988) foi o primeiro a enfatizar a importância da inovação tecnológica na dinâmica do capitalismo, defendendo as novas combinaçôes. $\mathrm{Na}$ concepção schumpeteriana, tem-se a própria inovação como forma de evoluir e configurar as estruturas industriais.

Entretanto, o aparecimento de contribuições mais consistentes, na tentativa de incorporar as inovaçóes no aparato teórico do comércio mundial, ocorreu com as novas teorias de comércio internacional e na abordagem neosschumpeteriana.

Ao analisar as novas teorias de comércio internacional, Nakano (1994) conclui que a explicação para os novos padrôes de comércio e da competitividade surgiu com base no exame da interação estratégica entre empresas e governo. Os novos modelos incorporam concorrência imperfeita (oligopólios e concorrência monopolística) e fatores como barreiras à entrada, produtos diferenciados, economias de escala, learning-bydoing e progresso tecnológico.

A corrente de pensamento neosschumpeteriana tem sua preocupação central na lógica do processo de inovação e seus impactos na atividade econômica. Assim, como afirma Negri (2005), a tecnologia não é um bem livremente disponível para os neosschumpeteria- 
nos, e as diferenças tecnológicas e de capacidade inovativa entre os países são fundamentais para indicar a direção e o volume de comércio entre eles. Complementando essa informação, Tavares, Kretzer e Medeiros (2005) afirmam que, para os neosschumpeterianos, a inovação, tanto de processo quanto de produtos, é o único caminho de sobrevivência nos mercados cada vez mais competitivos. Assim, empresas e setores da economia que não procurarem investir em novas tecnologias para inovar tenderão a desaparecer nesses novos mercados.

A partir dos anos 1990, Michael Porter tentou revitalizar a ideia de vantagem competitiva das naçóes como fator explicativo para o fluxo de comércio internacional e incorporou elementos novos à teoria tradicional. Porter (1993), ao buscar as características que permitiriam a uma nação e às suas empresas criarem e manterem vantagem competitiva, identificou que os fatores de produção, condiçóes de demanda doméstica, estratégia, estrutura e rivalidade das empresas, bem como as indústrias de apoio, seriam os elementos que, combinados, levariam à vantagem competitiva da nação.

Quando se desloca o foco da análise dos determinantes da competitividade externa, da dotação de fatores de cada país para a questão da inovação, surge o papel primordial das empresas. Isso por- que a empresa representa o locus onde se desenvolvem os processos de incorporação tecnológica e de aprendizado. Além disso, as políticas públicas desenvolvidas pelos países, especificamente, podem ainda estimular o desenvolvimento de inovaçôes que levarão as empresas a maior competitividade internacional.

\subsection{Estrutura conceitual dos determinantes do desempenho exportador}

As empresas que têm maiores vantagens competitivas possuem também maior capacidade para competir ativamente no mercado, principalmente quando atuam no mercado internacional, o que reflete em um bom desempenho exportador. A estrutura conceitual de análise, na qual o setor de atuação da empresa (tradicional exportador ou não), os fatores externos (percebidos pelos administradores) e, principalmente, os recursos específicos das firmas (divididos em características e capacidades tecnológicas) são os atores-chave na definição do desempenho exportador, está ilustrada na Figura 1.

Assim, os condicionantes que supostamente impactam o desempenho exportador são estruturados em três tipos de fator: a) o setor de atuação da firma; b) os fatores externos em torno da empresa; e c) os recursos específicos de cada empresa. 
$\mathrm{O}$ fato de pertencer a um setor que, durante anos consecutivos, tem figurado na pauta de exportação do país pode, de certo modo, influenciar a competitividade da empresa no mercado externo, que permitirá a continuidade ou não no processo exportador. Isso porque, nesses setores, as vantagens comparativas do país e, consequentemente, das empresas, já estão estabelecidas.

Os fatores externos relacionam-se ao ambiente além dos limites da empresa, representados pelas oportunidades e ameaças e que não estão sob o controle da administração. Considerados relevantes, Pipkin (2003) os divide em quatro fatores principais: sociais e culturais; políticos e legais; tecnológicos e econômicos. Nos negócios internacionais, o ambiente externo à empresa é um dos componentes principais para a administração. Os fatores externos (econômico, político e sociocultural) podem representar barreiras de entrada que protegem o mercado estrangeiro de novos concorrentes e que, normalmente, só são superados a custos altos (Baldauf; Cravens; Wagner, 2000). Esses fatores externos apareceram

\section{Figura 1_Condicionantes do desempenho exportador de uma empresa}

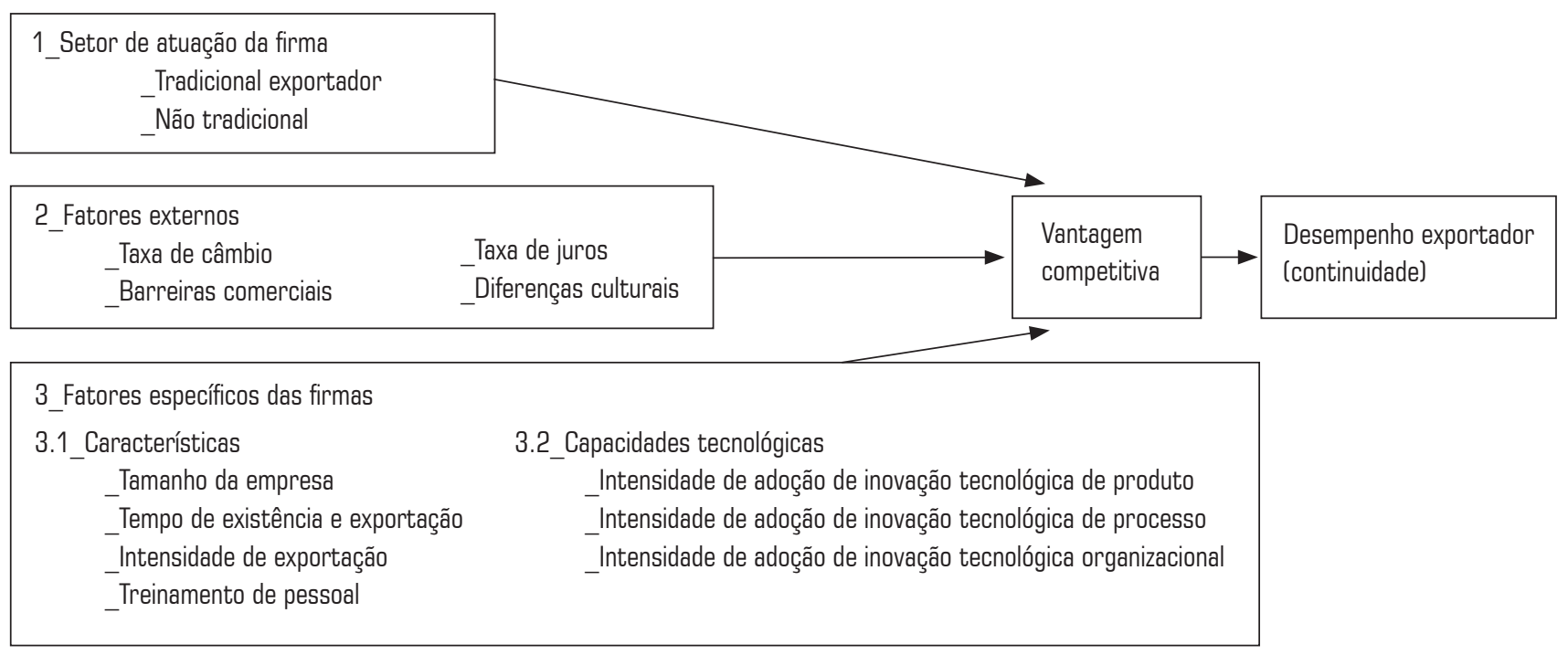

Fonte: Elaboração própria com base em Aaby e Slater (1989), Baldauf; Craven; Wagner (2000) e Majocchi; Bacchiocchi; Mayrhofer (2005). 
como determinantes do desempenho exportador em alguns estudos (Baldauf; Cravens; Wagner, 2000; Calantone et al., 2006; Majocchi; Bacchiocchi; Mayrhofer, 2005).

Os recursos específicos da firma são representados por dois fatores: características das firmas e capacidades tecnológicas. As características das firmas podem condicionar melhor desempenho da organização (Alvarez, 2004; Baldaulf; Cravens; Wagner, 2000; Bijmolt; Zwart, 1994; Lefebvre; Lefebvre, 2001). Em um contexto de mercado internacional, foram investigadas várias características da firma, incluindo tamanho, número de empregados, vendas totais, experiência em exportação, número de países para os quais a empresa exporta e presença de departamentos especializados em exportação. Os resultados desses estudos não são homogêneos, aparecendo desde associaçóes positivas com o desempenho exportador até associaçóes negativas ou nenhum tipo de associação.

Além das características das firmas anteriormente discutidas, têm-se ainda um recurso específico da firma relevante que é o investimento em inovação tecnológica. Esse envolve desenvolvimento de produtos novos para o mercado externo, aumento da produtividade e/ou redução nos custos e, frequen- temente, é mencionado na literatura como ativo que pode proporcionar a uma empresa posição competitiva mais forte em mercados estrangeiros (Alvarez, 2004; Araújo; Pianto, 2006; Lefebvre; Lefebvre, 2001; Negri, 2005; Negri; Freitas, 2004; Paiva; Mello, 1999; Wilkinson; Brouthers, 2006).

\section{3_Metodologia}

\section{1_Área de estudo, coleta e fonte de dados}

A área de estudo escolhida para desenvolver este trabalho é uma das dez regióes de planejamento que compóem o Estado de Minas Gerais, isto é, a Região Sul. Essa região é composta de, aproximadamente, 155 municípios (de um total de 853 municípios mineiros), cuja maioria constitui-se de pequenas cidades. A agricultura ainda é atividade das mais relevantes, capitaneada pela cultura do café; essa região tem também uma das principais bacias leiteiras do país (Guia Sul Mineiro, 2007). A população da região do Sul de Minas é a segunda mais populosa, com 2,6 milhôes de moradores (Fundação João Pinheiro, 2007). Dados do Ministério do Desenvolvimento, Indústria e Comércio Exterior (Brasil, 2008) dão conta de que, das 1.728 empre- 
sas que exportaram em Minas Gerais, no ano de 2008, $325(18,8 \%)$ pertenciam à regiấo do Sul de Minas, a segunda maior participação do Estado.

Os dados obtidos foram de natureza primária, coletados por meio de questionários estruturados, aplicados às pequenas e às médias empresas exportadoras da região Sul do Estado de Minas Gerais. Disponibilizaram-se três opçóes de encaminhamento de resposta: via email, via fax e agendamento de visita.

\section{2_População e amostra}

Como a pesquisa envolveu a questão da continuidade e pelo fato de as informaçôes disponíveis pelo Ministério do Desenvolvimento, Indústria e Comércio Exterior (MDIC) serem apenas de anos recentes, o ano de 2003 foi tomado como base (ou seja, as 210 empresas sul-mineiras exportadoras naquele ano). Assim, as empresas classificadas como exportadoras contínuas foram aquelas que exportaram todos os anos, de 2003 até 2008, e as classificadas como descontínuas, as que exportaram pelo menos três anos, entre 2003 e 2008, consecutivos ou não.

Foram descartadas do estudo as empresas que exportaram exclusivamente no ano de 2003, as que exportaram somente dois anos entre 2003 e 2008 e as de grande porte exportador, totalizando
93 empresas descartadas. Para a pesquisa, interessavam somente as pequenas e as médias exportadoras contínuas e descontínuas. Tomando como base o ano de 2003, tem-se, então, uma população de empresas sul-mineiras exportadoras contínuas e descontínuas, da ordem de 117 empresas.

Para a definição do tamanho da amostra, empregou-se a fórmula para populaçóes finitas, admitindo um nível de confiança de $90 \%$, com o valor críti$\operatorname{co~} z=1,64$, um erro de estimação $(\varepsilon)$ de 0,05 e $\mathrm{p}=\mathrm{q}=0,50$ (na hipótese de se admitir o maior tamanho da amostra, porquanto não se conhecem as proporçóes estudadas) e obteve-se uma estimativa de 77 empresas a ser amostradas. Destas, 55 foram exportadoras contínuas e 22, exportadoras descontínuas.

\section{3_Descrição e caracterização das diferenças entre empresas exportadoras contínuas e descontínuas}

Para comparar as características e a intensidade de adoção de tecnologia de empresas exportadoras contínuas e descontínuas, empregaram-se testes estatísticos paramétricos e não paramétricos, conforme o tipo de dado. Nos dados observados que produziram variáveis aleatórias numéricas (respostas numéricas) e medição por meio de contagem, utilizaram-se 
testes paramétricos. Já nos dados observados que produziram variáveis aleatórias categorizadas (respostas categorizadas) e medição por escala ordinal, empregaram-se testes não paramétricos.

Nas variáveis numéricas, utilizouse do teste $\mathrm{t}$ de comparação entre duas médias (paramétrico). Para as variáveis medidas em escala ordinal, optou-se pelo teste não paramétrico de WilcoxonMann-Whitney, considerado alternativa muito útil para o teste paramétrico t.

As variáveis relacionadas com os fatores externos à empresa são associadas com o caráter político-econômico e cultural. Foram avaliadas com base na importância atribuída pelo proprietário ou responsável/gerente de exportação da empresa a quatro itens: taxa de câmbio (TXC), barreiras comerciais às suas exportaçóes (BC), taxa de juros (TXJ) e diferenças culturais (DC). Todas foram medidas em escala ordinal de cinco categorias, em que 1 correspondeu a "pouco importante" e 5 a "muito importante". Neste caso, pressupóe-se relação negativa entre a percepção dos administradores em relação aos fatores externos e as chances de as empresas serem exportadoras contínuas. Ou que, quanto maior a importância percebida pelo proprietário ou responsável/gerente de exportação dos fatores externos que influenciam a sua or- ganização, menores serão as chances de a empresa ser uma exportadora contínua, conforme estabelecido em estudos anteriores como os de Ali (2004), Baldauf, Cravens e Wagner (2000), Calantone et al. (2006) e Markwald e Puga (2002).

Com relação à primeira variável dos fatores específicos da firma, características da empresa, essa é avaliada mediante nove indicadores, a saber:

_tamanho da empresa: número de empregados (NE) e faturamento anual (ano de 2008, em $\mathrm{R} \$$, por faixa) $(\mathrm{F})$;

_tempo de existência e tempo de exportação: idade da empresa (em anos) (I); números de anos de experiência internacional (EXME);

_intensidade de exportação: \% das vendas para o mercado externo (PVE); diversificação de produtos externos (quantidade de produtos destinados ao mercado externo) (DP); números de países para os quais a empresa exporta (NP); vendas anuais externas (em $\mathrm{R} \$$, por faixa $)(V E)$;

_treinamento de pessoal: treinamento de funcionário $($ dummy $=1 \mathrm{se}$ investe em treinamento; $=0$, caso contrário - TF). 
Esperava-se relação positiva entre o tamanho da empresa (NE e F), como nos estudos de Alvarez (2004), Baldauf, Cravens e Wagner (2000), Dhanaraj e Beamish (2003) e Nassimbeni (2001), e o desempenho exportador de uma empresa, embora tenha diferentes medidas para se dimensionar. Então, quanto maior o tamanho da empresa, maior a chance de a empresa se tornar uma exportadora contínua. Vantagens associadas com economias de escala, especialização, acesso a recursos financeiros, mão de obra especializada e capacidade de correr riscos estão entre as razóes para explicar por que empresas de maior porte tendem a melhor desempenho nos mercados internacionais.

Quanto ao tempo de existência da empresa e sua experiência em mercados externos, sua relação com exportadora contínua também é positiva. Empresas que atuam há mais tempo nos mercados nacional (I) e internacional (EXME) têm suas chances aumentadas de ser exportadoras contínuas, embora essa relação possa produzir resultados contraditórios. Por um lado, empresas maduras podem ter acumulado estoque de conhecimentos e construído capacidade para entrar nos mercados estrangeiros (Majocchi; Bacchiocchi; Mayrhofer, 2005). Por outro, empresas mais jovens podem ser mais proativas, flexíveis e agressivas para penetrar nos mercados exteriores (Lefebvre; Lefebvre, 2001).

A empresa exportadora aumenta a probabilidade de ser contínua no processo de internacionalização, quanto maior sua intensidade de exportação. Assim, quanto maiores os fatores relacionados à porcentagem de vendas externas (PVE), volume de vendas externas (VE), diversificação de produtos (DP) e número maior de países compradores (NP), maiores as chances de as empresas serem exportadoras contínuas, visto que ela está focada não somente no mercado nacional, como também no mercado internacional. Dessa forma, as empresas tendem a diversificar suas linhas de produto para o mercado externo e a ter maior número de mercados compradores.

Outra variável importante é treinamento de pessoal. Empresas que investem em qualificação de mão de obra demonstram maior preocupação com a questão da qualidade, requisito essencial para a permanência da empresa em mercados internacionais.

Com relação à intensidade de inovação tecnológica, o conceito adotado foi o mesmo estabelecido pela Organização para Cooperação Econômica e Desenvolvimento (OCDE) e publicado no Brasil pela Financiadora de Estudos 
e Projetos - FINEP (2004), que estabelece três tipos de inovação: a) inovação de produto; b) inovação de processo; e c) inovaçóes organizacionais.

Assim, a intensidade de inovação de produto $\left(\mathrm{INT}_{\mathrm{IP}}\right)$ constituiu-se de seis indicadores: produto novo para a empresa, mas já existente no mercado (IPA; $\mathrm{INT}_{1}$ ); produto novo para o mercado nacional (IPB; $\mathrm{INT}_{2}$ ); produto novo para o mercado internacional (IPC; $\mathrm{INT}_{3}$ ); mudança de design (IPD; $\mathrm{INT}_{4}$ ); mudança de embalagem (IPE; INT I $_{5}$, e aperfeiçoamento tecnológico (IPF; $\mathrm{INT}_{6}$ ).

A intensidade de inovação de processo $\left(\mathrm{INT}_{\mathrm{PR}}\right)$ também foi medida por seis indicadores: processos tecnológicos novos para sua empresa, mas já existentes no setor (IPRA, INT I $_{7}$; processos tecnológicos novos para o setor de atuação (IPRB; $\mathrm{INT}_{8}$ ); aquisição de novas máquinas (IPRC; $\mathrm{INT}_{9}$ ); introdução de controle de qualidade (IPRD; INT $_{10}$ ); introdução de tecnologia da informação (IPPRE; $\mathrm{INT}_{11}$ ), e realização de pesquisa de mercado (IPRF; INT $_{12}$ ).

Por fim, a intensidade de inovação organizacional $\left(\mathrm{INT}_{\mathrm{IO}}\right.$ ) foi avaliada mediante sete indicadores: implementação de técnicas avançadas de gestão (IOA; $\mathrm{INT}_{13}$ ); implementação de significativas mudanças na estrutura organizacional (IOB; $\mathrm{INT}_{14}$ ); mudanças sig- nificativas nos conceitos e/ou práticas de marketing (IOC; INT $_{15}$ ); mudanças significativas nos conceitos e/ou práticas de comercialização (IOD; $\mathrm{INT}_{16}$ ); implementação de novos métodos e gerenciamento, visando atender a normas de certificação (ISO 9000, ISO 14000 , etc.) (IOE; $\mathrm{INT}_{17}$ ); treinamento de funcionários em comércio exterior (IOF; $\mathrm{INT}_{18}$ ), e contratação de mão de obra especializada em comércio exterior $\left(\mathrm{IOG}\right.$; $\mathrm{INT}_{19}$ ).

A variável INT (Intensidade) é a que mede a intensidade com que a empresa adota determinadas açóes com relação à adoção de tecnologia (IPA, ..., IPF; IPRA,..., IPRF; IOA..., IOG), representada pela resposta do proprietário ou responsável/gerente de exportação na seguinte escala: igual a 1 , se a intensidade for nula; igual a 2 , se a intensidade for baixa; igual a 3 , se a intensidade for ligeiramente baixa; igual a 4 , se a intensidade for ligeiramente alta, e igual a 5, se a intensidade for alta.

\section{4_Descrição e operacionalização das variáveis nos determinantes do desempenho exportador}

Para verificar se os fatores externos e, principalmente, os recursos específicos da firma relacionados à inovação tecnológica determinam o desempenho 
exportador (continuidade de exportação), é utilizado um modelo logit binomial. Segundo Stock e Watson (2004), o modelo logit, com variável dependente binária Y e múltiplos regressores, é dado por:

$$
\begin{aligned}
& P_{i}\left(Y=1 / X_{1}, X_{2}, \ldots, X_{k}\right)=F\left(\beta_{0}+\beta_{1} X_{1}+\beta_{2} X_{2}+\ldots+\beta_{k} X_{k}\right) \\
& P_{i}\left(Y=1 / X_{1}, X_{2}, \ldots, X_{k}\right)=\frac{1}{1+e^{-\left(\beta_{0}+\beta_{1} X_{1}+\beta_{2} X_{2}+\ldots+\beta_{k} X_{k}\right)}}
\end{aligned}
$$

Essa é a forma funcional de distribuição acumulada logística em que: $\mathrm{P}_{\mathrm{i}}$ é a probabilidade de a empresa ser uma exportadora contínua; $\beta$ são parâmetros a ser estimados, e $e$ é a base dos logaritmos naturais. $\mathrm{O}$ fato de o modelo logit ser baseado na função de probabilidade logística cumulativa garante que as estimativas de probabilidade cairão dentro do intervalo de zero a um.

A variável dependente teve o valor 1, caso a empresa fosse uma exportadora contínua (ou permanente), no período de 2003 a 2008, e 0, se a empresa fosse uma exportadora descontínua (exportou somente em três anos, consecutivos ou não, nesse mesmo período). Assim, o desempenho exportador da firma é representado por essa variável dicotômica, e três equaçóes distintas foram estimadas.
Em vários estudos, analisou-se a relação entre a inovação tecnológica e o desempenho exportador, sendo observada relação positiva entre eles. Lefebvre e Lefebvre (2001) encontraram evidência de que as capacidades tecnológicas e comerciais de uma empresa são significativas e positivamente relacionadas com o desempenho exportador. Alvarez (2004) identificou a inovação de processo por outsourcing como uma das fontes de sucesso de pequenas e médias empresas em exportação. No caso de firmas brasileiras, Negri (2005) evidenciou a tecnologia como fator importante para o desempenho exportador.

\section{4_Resultados}

\section{1_Comparação entre as empresas exportadoras contínuas e descontínuas}

As médias das variáveis aleatórias numéricas (respostas numéricas) para cada amostra de empresas, bem como o respectivo valor $p$, estão sumarizadas na Tabela 1.

A estatística do teste $t$ revela que as diferenças significativas ocorrem somente em três variáveis. Assim, os resultados indicam que houve diferenças estatisticamente significativas, entre as médias de empresas contínuas e des- 
Tabela 1_Resultados da comparação entre características das empresas exportadoras contínuas e descontínuas do Sul de Minas Gerais, entre 2003 e 2008

\begin{tabular}{|c|c|c|c|}
\hline Características da firma & $\begin{array}{l}\text { Exportadoras } \\
\text { contínuas }\end{array}$ & $\begin{array}{l}\text { Exportadoras } \\
\text { descontínuas }\end{array}$ & Valor de $\mathbf{p}$ \\
\hline Idade (I) & 24,13 & 20,77 & 0,3547 \\
\hline Experiência em mercado externo (EXME) & 13,45 & 9,95 & $0,0720^{*}$ \\
\hline Número de empregados (NE) & 213,25 & 55,27 & $0,0029^{* * *}$ \\
\hline Número de países para os quais exporta (NP) & 8,87 & 5,23 & $0,0830^{*}$ \\
\hline \% das vendas externas (PVE) & 33,14 & 20,43 & 0,1295 \\
\hline Diversificação de produtos (DP) & 11,40 & 4,09 & 0,3162 \\
\hline
\end{tabular}

Fonte: Dados da pesquisa. $\left(\mathrm{n}=77 ;{ }^{*} \mathrm{p}<0,10 ;{ }^{* *} \mathrm{p}<0,05 ;{ }^{* * *} \mathrm{p}<0,01\right)$.

contínuas, para experiência em mercado externo (EXME, $p=0,0720$ ), número de empregados (NE, $p=0,0029)$ e número de países para os quais a empresa exporta (NP, $p=0,0830$ ). Em outros termos, as empresas contínuas têm um escore de média em NE, NP e EXME maior que as empresas descontínuas.
Os resultados do teste WilcoxonMann-Whitney (W-M-W) para comparação entre as duas amostras de empresas (contínuas - CONT e descontínuas - DESC) com relação aos fatores externos (Tabela 2) sugerem que não existe diferença estatisticamente significativa entre a importância da taxa de câmbio (TXC,

Tabela 2_Resultados da comparação entre empresas exportadoras contínuas e descontínuas do Sul de Minas Gerais, entre 2003 e 2008, com relação a fatores externos

\begin{tabular}{|c|c|c|c|c|}
\hline Variáveis & $\begin{array}{c}\text { Exportadoras } \\
\text { contínuas }\end{array}$ & $\begin{array}{l}\text { Exportadoras } \\
\text { descontínuas }\end{array}$ & Teste Z & Valor de p \\
\hline Taxa de câmbio (TXC) & 4,53 & 4,59 & $-0,0420$ & 0,9665 \\
\hline Barreiras comerciais (BC) & 3,60 & 3,32 & $-0,7603$ & 0,4471 \\
\hline Taxa de juros (TXJ) & 3,89 & 3,55 & $-1,0208$ & 0,3074 \\
\hline Diferenças culturais (DC) & 2,93 & 2,68 & $-0,8490$ & 0,3958 \\
\hline
\end{tabular}

Fonte: Dados da pesquisa. $\left(\mathrm{n}=77 ;{ }^{*} \mathrm{p}<0,10 ;{ }^{* *} \mathrm{p}<0,05 ;{ }^{* * *} \mathrm{p}<0,01\right)$. 
$p=0,9665)$, barreiras comerciais (BC, $p=0,4471$ ), taxa de juros (TXJ, $p=0,3074$ ) e diferenças culturais (DC, $p=0,3958$ ), para os dois tipos de empresa exportadora.

Os dois tipos de empresa (CONT/ DESC) exibiram visóes semelhantes concernentes aos fatores externos à empresa e consideraram como relativamente muito importantes os efeitos do ambiente externo, podendo prejudicar a atuação no mercado internacional. A frequência absoluta nas escalas ordinais maiores para a importância das variáveis ambientais, 4 (muito importante) e 5 (muitíssimo importante), foi alta para os dois tipos de empresa. Assim, entre os fatores ambientais, menor importância foi nomeada para as diferenças culturais e maior importância para a taxa de câmbio. Esses resultados, ao nomear relativa importância aos fatores externos, são semelhantes aos encontrados por Ali (2004) e Markwald e Puga (2002), que divergem das conclusões do estudo de Baldauf, Cravens e Wagner (2000).

Ressalta-se que as empresas exportadoras podem não estar interessadas em fatores externos ao entrarem no mercado internacional, mas, na permanência no mercado externo, esses fatores tornam-se importantes na medida em que há ampliação ou diversificação do nú- mero de países para os quais exportam (Baldauf; Cravens; Wagner, 2000).

O teste W-M-W, utilizado para comparação entre os dois tipos de empresa (CONT/DESC) em relação às inovaçôes tecnológicas (Tabela 3) mostrou que, embora haja diferenças na adoção de tecnologias, os exportadores contínuos inovam mais que os exportadores descontínuos em produto novo para o mercado internacional (IPC, $p=0,0257$ ), mudança de embalagem (IPE, $p=0,0951$ ) aperfeiçoamento tecnológico (IPF, $p=0,0389$ ), processos tecnológicos novos para o setor de atuação (IPRB, $p=0,0161$ ), aquisição de novas máquinas (IPRC, $p=0,0747$ ), introdução de controle de qualidade (IPRD, $p=0,0197$ ), introdução de tecnologia da informação (IPRE, $p=0,0184$ ), realização de pesquisa de mercado (IPRF, $p=0,0375$ ), implementação de técnicas avançadas de gestâo (IOA, $p=0,0375$ ), implementação de significativas mudanças na estrutura organizacional (IOB, $p=0,0887$ ), mudanças significativas nos conceitos e/ou práticas de comercialização (IOD, $p=0,0075)$, implementação de novos métodos e gerenciamento visando atender a normas de certificação (IOE, $p=0,0093$ ), treinamento de funcionários em comércio exterior (IOF, $p=0,0087$ ) e contratação de mão de obra especializada em comércio exterior (IOG, $p=0,0028$ ). 
Tabela 3_Resultados da comparação entre empresas exportadoras contínuas e descontínuas do Sul de Minas Gerais, entre 2003 e 2008 , com relação à adoção tecnológica

\begin{tabular}{|c|c|c|c|c|}
\hline Variáveis & $\begin{array}{l}\text { Exportadoras } \\
\text { contínuas }\end{array}$ & $\begin{array}{l}\text { Exportadoras } \\
\text { descontínuas }\end{array}$ & Teste Z & Valor de p \\
\hline \multicolumn{5}{|l|}{ Inovaçáo de produto } \\
\hline Produto novo para empresa (IPA) & 3,58 & 3,09 & $-1,5146$ & 0,1299 \\
\hline Produto novo p/ o mercado nacional (IPB) & 3,40 & 2,73 & $-1,5683$ & 0,1168 \\
\hline Produto novo p/ mercado internacional (IPC) & 3,20 & 2,27 & $-2,2312$ & $0,0257^{* *}$ \\
\hline Mudança de design (IPD) & 3,05 & 2,95 & $-0,3361$ & 0,7368 \\
\hline Mudança de embalagem (IPE) & 2,82 & 2,32 & $-1,6693$ & $0,0951^{*}$ \\
\hline Aperfeiçoamento tecnológico (IPF) & 3,64 & 3,00 & $-2,0647$ & $0,0389^{* *}$ \\
\hline \multicolumn{5}{|l|}{ Inovação de processo } \\
\hline Processos tecnológicos novos (IPRA) & 3,49 & 3,09 & $-1,5206$ & 0,1284 \\
\hline Processos tecnológico para o setor (IPRB) & 3,56 & 2,82 & $-2,4059$ & $0,0161^{* *}$ \\
\hline Aquisição de novas máquinas (IPRC) & 3,56 & 3,00 & $-1,7824$ & $0,0747^{*}$ \\
\hline Controle de qualidade (IPRD) & 3,98 & 3,23 & $-2,3328$ & $0,0197^{* *}$ \\
\hline Tecnologia da Informação (IPRE) & 3,76 & 2,95 & $-2,3569$ & $0,0184^{* *}$ \\
\hline Pesquisa de mercado (IPRF) & 3,69 & 2,54 & $-2,4406$ & $0,0147^{* *}$ \\
\hline \multicolumn{5}{|l|}{ Inovação organizacional } \\
\hline Técnicas avançadas de gestão (IOA) & 3,69 & 3,09 & $-2,0800$ & $0,0375^{* *}$ \\
\hline Mudanças estratégicas organizacionais (IOB) & 3,49 & 3,00 & $-1,7022$ & $0,0887^{*}$ \\
\hline Mudanças de marketing (IOC) & 3,40 & 2,91 & $-1,5929$ & 0,1112 \\
\hline Mudanças de comercialização (IOD) & 3,62 & 2,95 & $-2,6730$ & $0,0075^{* * *}$ \\
\hline $\begin{array}{l}\text { Novos métodos e gerenciamento p/ atender } \\
\text { à certificaçáo (IOF) }\end{array}$ & 3,49 & 2,54 & $-2,6001$ & $0,0093^{* * *}$ \\
\hline Treinamento dos funcionários em comércio exterior (IOG) & 3,07 & 2,23 & $-2,6254$ & $0,0087^{* * *}$ \\
\hline Máo de obra especializada em comércio exterior (IO7) & 2,73 & 1,77 & $-2,9857$ & $0,0028^{* * *}$ \\
\hline
\end{tabular}


Os resultados das diferenças entre os dois tipos de empresa amostrada (CONT./DESC.) não chegam a surpreender, dado que a competição é crescentemente baseada em inovações tecnológicas, e as firmas que quiserem permanecer nos mercados internacionais devem inovar constantemente. Assim, como apontado por Lefebvre e Lefebvre (2001), as variáveis representativas da capacidade tecnológica como aumento no nível de automação, modernização de maquinaria e equipamento, normas e padróes de qualidade internacionais, intensidade de conhecimentos técnicos e experiência única são vistas como positivamente relacionadas com desempenho exportador no contexto de pequenas e médias empresas industriais. As empresas sul-mineiras exportadoras contínuas têm escore de média maior em quase todos os itens relacionados aos três tipos de inovação (produto, processo e organizacional), revelando um uso mais intensivo desses instrumentos inovativos.

A razão pelas quais algumas pequenas e médias empresas tendem a ser mais inovativas que outras está associada ao fato de que percebem o ambiente de forma mais dinâmica e competitiva. Assim, em longo prazo, elas são mais propensas a assumir mais riscos e implementar estratégias de inovação mais agressivas (relacionadas a processo e organizacionais) (Paiva; Mello, 1999).

\section{2_ Identificação dos fatores determinantes do desempenho exportador}

Os resultados da seção anterior sugerem que há diferenças significativas no comportamento das empresas de acordo com seu status de exportação (contínua/descontínua) para a adoção de inovação tecnológica. Assim, três modelos logit binários foram construídos para identificar empiricamente determinantes importantes do desempenho exportador (medido como a permanência na atividade exportadora), utilizando-se busca sequencial com a abordagem de eliminaçấo backward ("passo atrás").

O primeiro modelo (1) empregou como regressores somente as variáveis explicativas que melhor caracterizam as firmas como exportadoras: Set $=$ Setor, variável dummy (= 1 , se a empresa pertence a setor tradicional exportador; $=0$, caso contrário); $\mathrm{NE}$ = número de empregados da firma (variável designada para medir o tamanho da empresa); EXMEI = proporção da experiência da firma em mercados externos sobre a idade; $\mathrm{NP}=$ número de países para os quais a firma exporta; $\mathrm{VE}=$ volume das vendas externas e TF = treinamento de funcionários, variável 
dummy (= 1 , se a empresa investe em treinamento de pessoal; $=0$, caso contrário).

O modelo seguinte (2) testou, além das variáveis que caracterizam as firmas como exportadoras, aquelas que discriminaram as duas subamostras (contínuas/descontínuas) em relação à adoção de inovação tecnológica da seção anterior. Assim, somente mais duas variáveis foram incorporadas pelos métodos de seleção, ou seja, a variável IPR 2 = processos tecnológicos novos para o setor de atuação e a $\mathrm{IO} 4$ = mudanças significativas na estrutura organizacional. Todas as demais não contribuíram com a melhora da qualidade do modelo ou pioraram seu ajuste. Finalmente, o modelo 3 estimado teve como variáveis explicativas as que caracterizavam as empresas mais o construto geral criado a partir da soma dos itens que representavam a adoção de inovação tecnológica (IT, alfa de Cronbach=0,93).

Os resultados dos modelos logit binários com relação aos determinantes da empresa exportadora ser contínua ou descontínua, com a inclusão dos fatores selecionados, encontram-se na Tabela 4. Os critérios utilizados para a seleção de variáveis permitiram redução significativa das variáveis independentes iniciais.

Importante ressaltar, mais uma vez, que as variáveis que compunham os fatores externos (TXC, DC, BC e TXJ) não foram selecionadas por nenhum dos critérios adotados. Dessa forma, tais fatores (da forma como foram medidos) não podem ser determinantes no desempenho da empresa em relaçáo ao seu status de permanência na atividade exportadora.

Os resultados das análises do ajuste dos modelos de regressão foram satisfatórios em todos os modelos selecionados. O teste de qui-quadrado e o teste de Score foram altamente significativos $(p<0,001)$. O teste de Wald, mais sensível à violação da suposição de grande amostra de regressão logit, apresentou-se significativo, mas com $p<0,10$. Os modelos desenvolvidos ajustaram-se muito bem, com mais de $90 \%$ dos argumentos classificados corretamente. Com respeito ao teste de aderência de resíduos (deviance), que envolve comparação entre o modelo de interesse e um modelo mais complexo, todos os modelos apresentaram nível alto de ajuste. Os $p$-valores nas equaçóes 2 e 3 foram maiores que 0,90 . A análise seguinte permitiu predizer os determinantes de as empresas serem exportadoras contínuas.

A variável relacionada ao Setor (SET) foi incluída nos três modelos estimados e estatisticamente significativa somente em dois (modelos 2 e 3 ), sempre a $10 \%$ de significância. O fato de a 
Tabela 4_Resultados da análise de regressão logística para os determinantes de desempenho exportador de empresas contínuas e descontínuas do Sul de Minas, entre 2003 e 2008

\begin{tabular}{|c|c|c|c|}
\hline Variáveis independentes & Equação 1 & Equação 2 & Equação 3 \\
\hline Intercepto & $-4,0158^{*}$ & $-7,8925^{*}$ & $-9,3834^{*}$ \\
\hline \multicolumn{4}{|l|}{ 1. Setorial } \\
\hline Setor (SET) & $0,8745^{\mathrm{n}, \mathrm{s}}$ & $1,5086^{* * *}$ & $1,8743^{* * *}$ \\
\hline \multicolumn{4}{|l|}{ 2. Características das firmas } \\
\hline Tamanho (NE) & $0,0163^{* *}$ & $0,0142^{* *}$ & $0,0139^{*}$ \\
\hline Proporção experiência/idade (EXMEI) & $3,6485^{* *}$ & $3,0502^{*}$ & $3,1530^{*}$ \\
\hline \multicolumn{4}{|l|}{ Intensidade de exportação } \\
\hline Vendas anuais externas (VE) & $0,1294^{\mathrm{n}, \mathrm{s}}$ & $0,4050^{*}$ & $0,2786^{\mathrm{n}, \mathrm{s}}$ \\
\hline Número de países $\left(\mathrm{NP}^{2}\right)$ & $-0,0037^{* *}$ & $-0,0038^{* * *}$ & $-0,0037^{* *}$ \\
\hline Treinamento de pessoal (TP) & $1,2598^{\mathrm{n}, \mathrm{s},}$ & $0,0566^{\mathrm{n}, \mathrm{s}}$ & $0,0153^{\mathrm{n}, \mathrm{s}}$ \\
\hline \multicolumn{4}{|l|}{ 3. Capacidades administrativas } \\
\hline Processos tecnológicos novos para o setor de atuação (IPRA) & & $0,5756^{*}$ & \\
\hline Mudanças significativas nos conceitos e/ou práticas de comercialização (IOD) & & $0,7034^{*}$ & \\
\hline \multicolumn{4}{|l|}{ 4. Construto } \\
\hline Inovação tecnológica (SIT) & & & $0,0427^{\mathrm{n}, \mathrm{s}}$ \\
\hline LL Ratio & $38,2809^{* * *}$ & $45,1044^{* * *}$ & $47,9081^{* * *}$ \\
\hline Score & $27,9063^{* * *}$ & $31,7817^{* * *}$ & $33,4515^{* * *}$ \\
\hline Wald & $16,6216^{* * *}$ & $14,7963^{*}$ & $15,9479^{*}$ \\
\hline Deviance & 0,84 & 0,93 & 0,96 \\
\hline \% Concordância & 90,3 & 93,1 & 93,7 \\
\hline
\end{tabular}

Fonte: Dados da pesquisa. $\left(\mathrm{n}=77 ;{ }^{* *} \mathrm{p}<0,01 ;{ }^{* *} \mathrm{p}<0.05 ;{ }^{*} \mathrm{p}<0.10\right.$; n.s. năo significativo).

empresa pertencer a um setor tradicional exportador aumenta a probabilidade de ser uma exportadora contínua (em 4,5 vezes no modelo 2 e 6,5 vezes no modelo 3 , as chances das descontínuas), con- forme expectativa preliminar descrita na operacionalização das variáveis. Ou seja, empresas que pertencem a setores tradicionais da pauta de exportação brasileira tendem a ter vantagens comparativas 
e ser beneficiadas por políticas públicas. Esses fatos aumentam suas chances de permanecer nos mercados externos.

Com relação às características das firmas, dois indicadores são particularmente fortes determinantes do status de exportação: tamanho da empresa medido pelo número de empregados (NE) e a proporção experiência em mercados externos e idade da empresa (EXME/I).

Em tamanho da empresa, a variável faturamento $(\mathrm{F})$, embora correlacionada positivamente com a variável EXP, não foi selecionada para nenhuma das regressóes e, portanto, não permitiu nenhum tipo de inferência. Já a variável número de empregados (NE) foi estatisticamente significativa nas três equações analisadas. Esse resultado mostra que o tamanho da empresa (medido em termos do número de empregados) relaciona-se com o melhor desempenho exportador, mesmo para o caso em que ambas as amostras se constituem de pequenas e médias empresas. Ou seja, mesmo entre as pequenas e as médias empresas, as firmas maiores têm vantagem em entrar e permanecer em mercados internacionais. Isso se justifica porque empresas maiores possuem mais recursos ou facilidade de acesso a eles e tendem a alcançar desempenho mais eficaz em mercados externos, quando comparadas às suas contrapartes menores. Essa evidência é consistente com os resultados de alguns estudos empíricos anteriores (Alvarez, 2004; Baldauf; Cravens; Wagner, 2000; Dhanaraj; Beamish, 2003; Nassimbeni, 2001). De modo geral, o tamanho da firma influencia o desempenho exportador, embora as medidas utilizadas para dimensionar a firma sejam bastante divergentes.

A proporção experiência em mercados externos e idade da empresa (EXME/I) foi estabelecida porque a idade da empresa não chega a ser um fator que determina a permanência na atividade exportadora. De fato, o que vale é a relação entre a idade da empresa e o tempo em que ela já atua no mercado internacional. Pois, podem-se ter empresas antigas na atuação do mercado interno, mas inexperientes em mercados externos, como também empresas mais novas, mas que, desde que foram fundadas, já atuam no mercado exportador. Assim, empresas que já na sua origem criam infraestrutura para suportar operaçóes internacionais e que estão mais vinculadas à formação e à orientação internacionais desde cedo podem alcançar vantagens competitivas nos mercados exteriores. Essa variável (EXME/I) foi positiva e estatisticamente significativa nas três equaçóes. Empresas em que 
o tempo de atuação no mercado externo como proporção da idade da empresa foi maior têm as chances aumentadas de ser exportadoras contínuas.

Com relação à intensidade de exportação, optou-se pela utilização do volume de vendas (VE) em vez de percentagem de vendas (PVE) para entrar como variável explicativa, por estarem correlacionadas. Entretanto, VE mostrou-se estatisticamente significativa somente em um dos modelos apresentados (2), particularmente o que incorpora as capacidades administrativas também como regressores. Assim, pode-se inferir que vendas externas são determinantes do desempenho exportador somente quando são regredidas, combinadas com atitudes gerenciais, como a utilização de alguma inovação tecnológica ou a utilização de recursos financeiros públicos.

O número de países para os quais a empresa exporta (NP) foi utilizado nos modelos de regressão com uma transformação, ou seja, elevou-se a variável ao quadrado. Embora significativa nas equaçóes apresentadas, tal variável apresentou sinais negativos. Sendo assim, quanto maior o número de países para os quais a empresa exporta, ou melhor, quanto maior a diversificação do mercado externo, menor a chance de a empresa ser uma exportadora permanente. Isso contraria o que se esperava anteriormente (de que haveria relação positiva entre permanência exportadora e número de países para os quais a empresa exporta), porque diversificação de mercados compreende também maior volume de produção para atender a esses mercados, e empresas de menor porte são limitadas pela sua produção. A diversificação dos produtos (DP) mostrou-se não significativa para a permanência da empresa no mercado exterior em todos os modelos apresentados.

Treinamento de pessoal com a variável TF surpreendentemente não foi significativa em nenhuma das equaçóes propostas. Contudo, treinamento de funcionários, especificamente em operaçôes de exportação e não de forma geral, como proposto aqui, desencadeia melhor performance exportadora. Alvarez (2004) demonstrou, em estudo desenvolvido anteriormente, que a empresa que investe em treinamento de funcionários e em operaçóes específicas de exportação tem maior chance de permanecer no status de exportadora permanente. Esse resultado é semelhante ao de Pérez et al. (2007), em estudo sobre a influência da estratégia de expansão e das características das empresas sobre o resultado exportador. $\mathrm{O}$ autor concluiu que, quanto maior o número de empregados com 
responsabilidades associadas ao desenvolvimento operacional de comércio exterior, maior a tendência ao crescimento das vendas externas (medida da performance exportadora).

Entre todos os itens que foram discriminantes das empresas exportadoras contínuas e esporádicas, somente dois explicam positiva e significativamente as diferenças da permanência das empresas no mercado exportador: inovação de método por processos tecnológicos novos para o setor de atuação e inovação organizacional por mudanças significativas nos conceitos e/ou práticas de comercialização. Os outros itens que compóem a inovação tecnológica não determinam o sucesso na exportação.

Como explicar esses resultados tão divergentes da hipótese preliminar de que a intensidade de inovaçôes tecnológicas determina a permanência das empresas de pequeno porte no mercado externo?

Primeiro, pode-se discutir que as empresas de pequeno porte da região Sul de Minas pesquisadas são especializadas em determinados nichos de mercado e de produto que não requerem grande esforço inovador, como, por exemplo, café em grãos e pedras quartzito. Além disso, em estudos anteriores, nos quais foram analisados os impactos das inovações tecnológicas no desempenho ex- portador (Lefebvre; Lefebvre, 2001; Markwald; Puga, 2002; Nassimbeni, 2001; Negri; Freitas, 2004), encontrou-se resultado positivo de esforço inovador na probabilidade de a empresa ser exportadora ou não, mas não de permanecer na atividade exportadora. Também compatível com estudos anteriores (Alvarez, 2004; Pérez, 2007), os resultados mostraram que inovação tecnológica é útil para entrar em mercados internacionais. Entretanto, desempenho posterior requer ações inovadoras maiores em processos e organizacionais como esses relacionados a processos tecnológicos novos para o setor de atuação e inovação organizacional por mudanças significativas nos conceitos e/ou práticas de comercialização.

A questão entre inovação e desempenho exportador aparece, muitas vezes, na literatura, relacionada com o dilema entre definir se o processo de exportação leva à atividade inovadora ou, ao contrário, o fato de possuir atividade inovadora permite à empresa facilidade de acesso a mercados externos. Conforme constatado por Kannebley Júnior e Valeri (2006), ao compararem empresas brasileiras contínuas, descontínuas e desistentes no processo de exportação, aquelas que, antes da estreia no mercado internacional, tinham melhor performance produtiva (maior produtivida- 
de, maior escala e custos competitivos), apresentavam mais probabilidade de permanecer continuamente na atividade exportadora. Entretanto, os autores notaram que as dummies para inovação tecnológica não foram estatisticamente significativas para explicar a probabilidade de as empresas pertencerem à categoria de empresas contínuas, evidenciando que inovação tecnológica não explica a maior permanência no mercado exportador. Assim, as empresas amostradas podem até ser mais intensivas em ações inovadoras, mas essas ações não determinam sua permanência no status de exportadora contínua.

\section{5_Conclusões}

Os resultados mostraram que os fatores externos à empresa (taxa de câmbio, barreiras comerciais, taxa de juros e diferenças culturais) são considerados muito importantes para essas empresas, independentemente de serem exportadoras contínuas ou descontínuas. Ou seja, para empresários e administradores de empresas de menor porte que já tiveram a experiência de exportar seus produtos, a taxa de câmbio é considerada fator importante na competitividade externa, e as barreiras impostas para alguns produtos no mercado externo constituem obstáculos à entrada e à permanência na atividade exportadora.

Determinadas características das empresas (tamanho, experiência em mercados internacionais e número de países para os quais a empresas exportam) discriminam as duas amostras analisadas e exercem influência sobre o sucesso da empresa nos mercados exteriores onde atuam, confirmando resultados em investigaçóes anteriores. Assim, mesmo entre firmas de porte semelhante, o tamanho da empresa e a experiência em mercados externos são fatores determinantes da competitividade externa e da permanência na atividade exportadora. $\mathrm{O}$ mesmo ocorre com a variável setor, revelando que, para empresas que pertencem a setores que já são tradicionais na atividade exportadora, aumenta a probabilidade de se tornarem exportadoras contínuas. Setores com tradição exportadora são mais articulados e têm maior poder de barganha, sendo constantemente contemplados com programas públicos e privados (via representaçóes de classe).

Os resultados também apoiaram parcialmente a hipótese estabelecida de que empresas exportadoras contínuas são mais intensivas em ações de inovação tecnológica. Alguns itens relacionados a esses fatores mostraram distinguir as duas subamostras (CONT./DESC.), embora 
não tenham sido capazes de determinar a permanência da empresa na atividade exportadora. Quando se considera o fator específico da firma relacionado ao caráter inovador das empresas, percebe-se que as empresas contínuas inovam mais que as descontínuas. Entretanto, o efeito dessas inovaçóes sobre a maior probabilidade de permanência no mercado externo é bastante reduzido, sugerindo a ocorrência de algum efeito somente em inovação de processo, por processos tecnológicos novos para o setor de atuação e inovação organizacional, por meio de mudanças significativas nos conceitos e/ ou práticas de comercialização.

Assim, somente essas duas atividades explicam diferenças no desempenho exportador. $\mathrm{O}$ fato justifica-se porque as empresas amostradas são especializadas em nichos de mercado e produtos que não requerem grande esforço inovador, e, além do mais, a permanência na atividade exportadora ou o desempenho posterior à entrada depende mais de atividades inovadoras em processo e organizacional.

Concluindo, os fatores relacionados à intensidade de açôes relacionadas à adoção de inovação tecnológica têm itens que, de modo geral, discriminam as duas subamostras (CONT./DESC.), mas que não condicionam e explicam sua permanência no processo de expor- tação (medida de desempenho). Os fatores condicionantes ficaram entre aqueles relacionados às características das empresas, como tamanho, proporção experiência em mercados internacionais e idade da empresa, vendas externas e ao fato de a empresa pertencer a um setor já tradicional na atividade exportadora.

Embora com este estudo ampliese o conhecimento acadêmico para o entendimento dos determinantes do desempenho exportador, os resultados devem ser vistos como orientação para políticas públicas e para as próprias empresas, na busca de maior participação no mercado internacional. 


\section{Referências bibliográficas}

AABY, N. E.; SLATER, S. F.

Management influences on export performance: A review of the empirical literature 1978-88. International Marketing Review, New York, v. 6, n. 4, p. 7-26, 1989

ALI, M. Y. Impact of firm and management related factors on firm export performance. Journal of Asia Pacific Marketing, Bingley, v. 3, n. 2, p. 5-20, 2004.

ALVAREZ, R. Sources of export success in small and mediumsized enterprises: The impact of public programs. International Business Review, Boston, v. 13, p. 383-400, 2004.

\section{ANDERSEN, O.; KHEAM,}

L. S. Resource-based theory and international growth strategies: An exploratory study. International Business Review, Boston, v. 7, p. 163-184, 1998.

ANSOFF, H. I. Estratégia empresarial. São Paulo: McGrawHill do Brasil, 1977. 203 p.

ARAÚJO, B. C. P. O.; PIANTO, D. M. Potencial exportador das firmas industriais brasileiras. Brasília: IPEA, 2006. (Texto para discussão, 1176).
BALDAUF, A.; CRAVENS, D. W.; WAGNER, U. Examining determinants of export performance in small open economies. Journal of World Business, Greenwich, v. 35, n. 1, p. 61-79, 2000.

BARNEY, J. B. Firm resources and sustained competitive advantage. Journal of Management, Stillwater, v. 17, n. 1, p. 99-120, 1991.

BIJMOLT, T. H. A.; ZWART, P. S. The impact of internal factors on the export success of Dutch small and medium-sized firms. Journal of Small Business Management, Bingley, v. 32, n. 2, p. 69-83, Apr. 1994.

BRASIL. Ministério do Desenvolvimento, Indústria e Comércio Exterior. Integra da apresentaçāo da política de desenvolvimento produtivo. Brasília, 2008. 235 p. Disponível em: <http://www.mdic.gov.br/ sitio/>. Acesso em: 2 jul. 2010.

BURLAMAQUI, L.; PROENÇA, A. Inovação, recursos e comprometimento: Em direçâo a uma teoria estratégica da firma. Revista Brasileira de Inovação, Brasília, v. 2, n. 1, p. 79-110, jan./jun. 2003.
CALANTONE, R. J. et al. The influence of internal and external firm factors on international product adaptation strategy and export performance: A threecountry comparison. Journal of Business Research, Athens, v. 49, p. 176-185, 2006.

DHANARAJ, C.; BEAMISH, P. W. A resource-based approach to the study of export performance. Journal of Small Business Management, Bingley, v. 41, n. 3, p. $242-261,2003$.

\section{FINANCIADORA DE}

ESTUDOS E PROJETOS.

Manual de Oslo: Diretrizes para coleta e interpretação de dados sobre inovação. Brasília: FINEP, 2004. $136 \mathrm{p}$.

\section{FUNDAÇÃO JOÃO}

PINHEIRO. População por regióes. Belo Horizonte, 2007. Disponível em: <http://www.fjp. mg.gov>. Acesso em: 10 set. 2010.

GRANT, R. M. The resourcesbased theory of competitive advantage: Implications for strategy formulation. California Management Review, Davis, v. 33, n. 3, p. 114-135, 1991.
GUIA SUL MINEIRO. Cidades do Sul e Sudoeste de Minas Gerais. Disponível em: <http://www. guiasulmineiro.com>. Acesso em: 8 set. 2007.

KANNEBLEY JÚNIOR, S.; VALERI, J. Persistência e permanência na atividade exportadora: Uma análise empírica para as empresas indústrias brasileiras.

In: no comércio internacional. Brasília: IPEA, 2006.

LEFEBVRE, E.; LEFEBVRE, L. A. Innovative capabilities as determinants of export performance and behaviour: A longitudinal study of manufacturing SME's. In: KLEINLENECHT, A.; MONHEN, P. (Ed.). Innovation and firm performance: Econometric explorations of survey data. Palgrave: MacMiullan, 2001.

MAJOCCHI, A.; BACCHIOCCHI, E.; MAYRHOFER, U. Firm size, business experience and export intensity in SMEs: A longitudinal approach to complex relationships. International Business Review, Boston, v. 14, p. 719-738, 2005. 
MARKWALD, R.; PUGA, F.

P. Focando a política brasileira de promoção de exportaçóes. $O$ desafio das exportaçōes. Rio de Janeiro: BNDES, 2002.

NAKANO, Y. Globalização, competitividade e novas regras de comércio mundial. Revista de Economia Politica, Rio de Janeiro, v. 14 , n. 4, p. 56, out./dez. 1994.

NASSIMBENI, G. Technology, innovation capacity, and the export attitude of small manufacturing firms: A logit/tobit model. Research Policy, Amsterdam, v. 30, p. 245-262, 2001.

NEGRI, F. de. Inovação tecnológica e exportaçôes das firmas brasileiras. In: Encontro Nacional de Economia, 33., 2005, Natal. Anais... Natal: ANPEC, 2005. 1 CD-ROM.

NEGRI, J. A.; FREITAS, F. de. Inovação tecnológica, eficiência de escala e exportaçôes brasileiras. Brasília: IPEA, 2004. 20 p. (Texto para discussão, 1044).

PAIVA, F.; MELLO, S. B. de. Estratégia tecnológica e exportaçáo no setor de transformação industrial: Um estudo de competitividade em micros, pequenos e médios negócios. In: ENCONTRO DA ASSOCIAÇÃO NACIONAL DE PÓS-GRADUAÇÃO EM ADMINISTRAÇÃO, 23., 1999, Foz do Iguaçu. Anais... Foz do Iguaçu, 1999. 1 CD-ROM.

PENROSE, E. G. The theory of the growth of the firm. $2^{\text {nd }}$ ed. Oxford: Oxford University, 1980.
PÉREZ, F. L. et al. Influencia de la estratégia de expansíon internacional y de las características empresariales sobre el resultado exportador de la empresa. Tribuna de Economia, n. 837, p. 255-272, jul./ago. 2007.

PRAHALAD, C. K.; HAMEL, G. The core competence of the corporation. Harvard Business Review, Boston, p. 79-91, May/June 1990.

PIPKIN, A. Marketing internacional: Uma abordagem estratégica. São Paulo: Aduaneiras, 2003. 162 p.

PORTER, M. E. A vantagem competitiva das naçôes. Rio de Janeiro: Campus, 1993. 897 p.

SCHUMPETER, J. A. Teoria do desenvolvimento econômico: Uma investigação sobre lucros, capital, crédito, juro e o ciclo econômico. Sáo Paulo: Nova Cultural, 1988. 168 p.

\section{SERVIÇO BRASILEIRO \\ DE APOIO ÀS MICRO E PEQUENAS EMPRESAS. \\ Anuário do trabalho na micro e pequena empresa. Brasília: DIEESE, 2007. 272 p.}

Serviço BRASILEIRO de Apoio às Micro e Pequenas Empresas. A presença das micro e pequenas empresas na economia brasileira. São Paulo, 2008. Disponível em: <http://www.sebraesp.com.br/>. Acesso em: 15 ago. 2008.

STOCK, J. H.; WATSON, M. W. Econometria. São Paulo: A. Wesley, 2004. 485 p.
TAVARES, P. V.; KRETZER, J.; MEDEIROS, N. Economia neosschumpeteriana: Expoentes evolucionários e desafios endógenos da indústria brasileira. Revista Economia Ensaios,

Uberlândia, v. 19, n. 3, p. 127-155, dez. 2005.

WERNERFELT, B. A resourcebased view of the firm. Strategic Management Journal, Sussex, v. 5 , n. 2, p. 171-180, 1984.

WILKINSON, T.; BROUTHERS, L. E. Trade promotion and SME export performance. International Business Review, Boston, v. 15, p. 233-252, 2006.

E-mail de contato dos autores
rosa@dae.ufla.br
mfmgomes@ufv.br
jelima@ufv.br
$\begin{aligned} & \text { Artigo recebido em dezembro de 2010; } \\ & \text { aprovado em fevereiro de 2011. }\end{aligned}$

